\title{
CBX3 regulates efficient RNA processing genome-wide
}

\author{
Andrea Smallwood, ${ }^{1}$ Gary C. Hon, ${ }^{1}$ Fulai Jin, ${ }^{1}$ Ryan E. Henry, ${ }^{2}$ Joaquín M. Espinosa, ${ }^{2}$ \\ and Bing Ren ${ }^{1,3,4}$ \\ ${ }^{1}$ Ludwig Institute for Cancer Research, La Jolla, California 92093, USA; ${ }^{2}$ Howard Hughes Medical Institute and Department of \\ Molecular, Cellular, and Developmental Biology, University of Colorado, Boulder, Colorado 80309, USA; ${ }^{3}$ Department of Cellular \\ and Molecular Medicine, Moores Cancer Center, and Institute of Genomic Medicine, University of California San Diego, La Jolla, \\ California 92093, USA
}

\begin{abstract}
CBX5, CBXI, and CBX3 ( $\mathrm{HPl} \alpha, \beta$, and $\gamma$, respectively) play an evolutionarily conserved role in the formation and maintenance of heterochromatin. In addition, $C B X 5, C B X 1$, and $C B X 3$ may also participate in transcriptional regulation of genes. Recently, CBX3 binding to the bodies of a subset of genes has been observed in human and murine cells. However, the generality of this phenomenon and the role CBX3 may play in this context are unknown. Genome-wide localization analysis reveals $\mathrm{CBX} 3$ binding at genic regions, which strongly correlates with gene activity across multiple cell types. Depletion of CBX3 resulted in down-regulation of a subset of target genes. Loss of CBX3 binding leads to a more dramatic accumulation of unspliced nascent transcripts. In addition, we observed defective recruitment of splicing factors, including SNRNP70, to CBX3 target genes. Collectively, our data suggest a role for $\mathrm{CBX} 3$ in aiding in efficient cotranscriptional RNA processing.
\end{abstract}

[Supplemental material is available for this article.]

Once thought of as static components of heterochromatin, heterochromatin protein 1 family members (HP1s-CBX5, CBX1, and CBX3) are now known to function in a myriad of cellular processes, including DNA repair, gene regulation, and telomere function (Maison and Almouzni 2004; Hediger and Gasser 2006; Lomberk et al. 2006; Kwon and Workman 2008). SU(VAR)205 (HP1a), HP1b, and HP1c were first characterized as suppressors of position effect variegation (PEV) in Drosophila and, along with H3K9 methylation, were regarded as a hallmark of heterochromatin or repressed/silenced regions of the genome (Dillon 2004; Huisinga et al. 2006; Lomberk et al. 2006). More recently, CBX5, -1, and -3 have been assigned roles in repression of transcription at euchromatic genes (Hiragami and Festenstein 2005; Hediger and Gasser 2006; Kwon and Workman 2008). CBX proteins interact with and are recruited to specific loci by repressor proteins such as Retinoblastoma (Rb1) (Nielsen et al. 2001), IKZF1 (Ikaros) (Brown et al. 1997), and TRIM28 (KAP1/TIFß) (Ryan et al. 1999; Schultz et al. 2002). CBX1 has been implicated in silencing of POU5F1 during early myogenesis (Feldman et al. 2006). CBX3 has been linked to silencing at E2F- and MYC-responsive genes in $\mathrm{G}_{0}$ cells (Ogawa et al. 2002) and the repression of the progestin responsive MMTV promoter in breast cancer cells (Vicent et al. 2006). In conjunction with SUV39H1, CBX3 is also responsible for chromatinmediated repression of the $H I V-1$ gene (du Chene et al. 2007). Most recently, CBX3 recruitment, along with DNA and histone methylation, has been implicated in PIAS1-mediated FOXP3 repression in T-cell differentiation (Liu et al. 2010). Biochemical studies have shed light on potential mechanisms of action for CBX5, CBX1, and CBX3 in this context (Smallwood et al. 2007, 2008).

In recent years, evidence has accumulated to implicate HP1 proteins in transcriptional activation. In Drosophila, cytological and genome-wide location studies demonstrated that SU(VAR)205

\footnotetext{
${ }^{4}$ Corresponding author

E-mail biren@ucsd.edu

Article published online before print. Article, supplemental material, and publication date are at http://www.genome.org/cgi/doi/10.1101/gr.124818.111.
}

binds to large domains in pericentric regions, repeat dense regions, transposable elements, and the entire $\mathrm{X}$ chromosome in male flies (Fanti et al. 2003; Greil et al. 2003; de Wit et al. 2005, 2007). In addition, SU(VAR)205 associated with exon-dense active genes on chromosome arms (Greil et al. 2003; de Wit et al. 2005, 2007). SU(VAR)205 was shown to be necessary for transcription of heterochromatin associated genes (de Wit et al. 2007). SU(VAR)205 was also found to positively regulate transcript levels in euchromatin, most notably at the $H s p 70$ heat shock puff loci (Piacentini et al. 2003; Cryderman et al. 2005). Most recently, SU(VAR)205 has been found associated with the promoters of genes with stalled RNA polymerase II (Yin et al. 2011). In contrast, a separate study demonstrated that active genes bound by SU(VAR)205 have a lower expression level than unbound genes, suggesting a negative role in transcription for SU(VAR)205 (de Wit et al. 2005). HP1c was also mapped to $\sim 150$ targets in active euchromatin (Greil et al. 2003). It has also been suggested that HP1c can colocalize with poised Ser-5 phosphorylated RNA polymerase II (RNAP II) (Font-Burgada et al. 2008). More recently, it was demonstrated that HP1c plays a role in recruitment of the FACT histone chaperone complex to active regions of the Drosophila genome functioning to link RNAP II and FACT (Kwon et al. 2010).

In murine cells, CBX3 was found localized to the coding regions of several genes (Vakoc et al. 2005). In addition, a switch has been observed from CBX3 binding at active genes to CBX5 and/or CBX1 binding inactive genes in human cells (Smallwood et al. 2007; Mateescu et al. 2008). This suggests distinct and complementary roles for different members of this family of proteins. However, low-resolution studies in the mouse and humans suggests that CBX5, -1 , and -3 may have similar overlapping binding profiles (Vogel et al. 2006). It was previously shown that concurrent overexpression of CBX5, -1, and -3 in ECR-293 cells resulted in up-regulation of four genes, although it was not determined if these were direct effects (Hwang and Worman 2002). In addition, CBX3 has been implicated in alternative splicing for a small subset of genes (Saint-Andre et al. 2011). To date, the exact nature and mechanism by which heterochromatin protein 1 family members 
influence gene regulation remains unclear. Genome-wide knowledge of specific gene targets would be an invaluable tool for understanding the mechanism of CBX3 gene regulation.

In the current study, we comprehensively determined CBX3 binding sites in the human genome, with the use of genome-wide location analysis, to gain a clearer picture of $\mathrm{CBX} 3$ action in gene regulation. We demonstrated that $\mathrm{CBX} 3$ localizes to the gene body of active genes in multiple cell lines and that its binding positively correlates with gene activity. Loss of CBX3 results in a decrease in transcript level of a specific subset of target genes. Surprisingly, CBX3 is enriched at exonic sequences, and loss of CBX3 binding led to an increase in unspliced transcripts of its target genes. Loss of $\mathrm{CBX} 3$ also diminished the recruitment of splicing factors to gene bodies, consistent with the observed splicing defects. Thus, CBX3 appears to promote optimal cotranscriptional RNA processing through recruitment of the splicing machinery. Taken together, this study brings to light a novel role for the heterochromatin protein $\mathrm{CBX} 3$ in gene regulation, providing a functional link between transcription, chromatin, and RNA processing.

\section{Results}

\section{Genome-wide localization of CBX3} to the gene body of active genes

CBX3 was previously found in the gene body of a few active mammalian genes (Vakoc et al. 2005; Smallwood et al. 2007). To get a clearer picture of CBX3 localization on a genome-wide basis, we performed ChIP-chip and ChIP-seq analysis in the human colorectal carcinoma cell line HCT116 (Johnson et al. 2007). Two biological replicates of CBX3 immunoprecipitations were analyzed by ChIPseq, and the results correlated well. In addition, two independent biological replicates were used for ChIP-chip analysis with the NimbleGen and ENCODE platforms; all analyses yielded the same results. We found CBX3 binding was commonly confined within the transcribed gene body but was also found spanning larger chromosomal regions encompassing one or more genes (Supplemental Fig. S1A). In fact, analysis revealed that genome-wide $89 \%$ of CBX3 occupied sequences are intragenic (Fig. 1A). To determine if CBX3 binding correlates with gene activity, we grouped HCT116 genes into three tiers by expression. Enrichment of CBX3 binding was then calculated for a region encompassing $10 \mathrm{~kb}$ upstream of the transcription start site (TSS) and $10 \mathrm{~kb}$ downstream from the $3^{\prime}$ end.
A

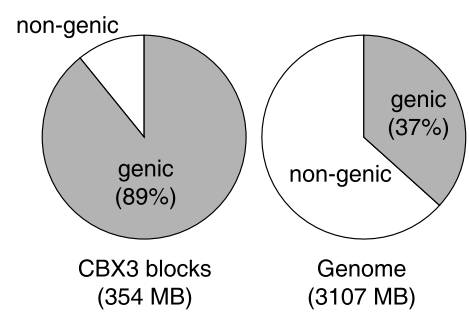

C

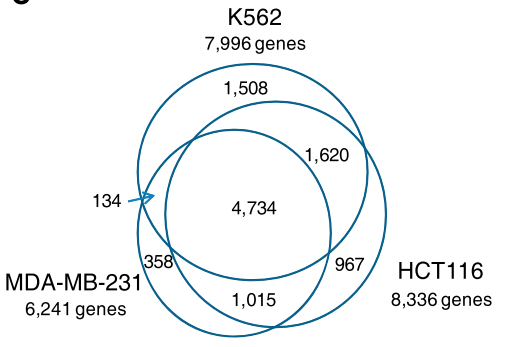

E

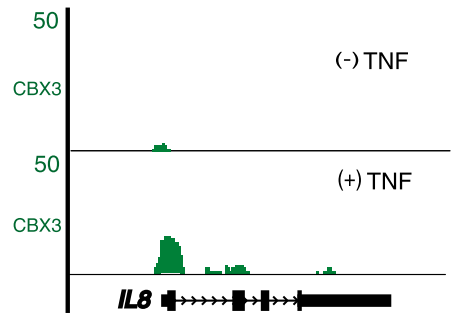

B

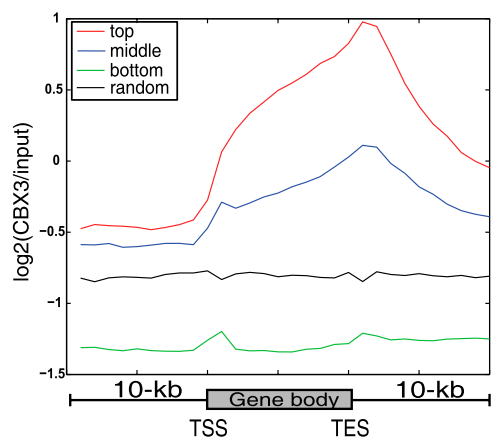

D
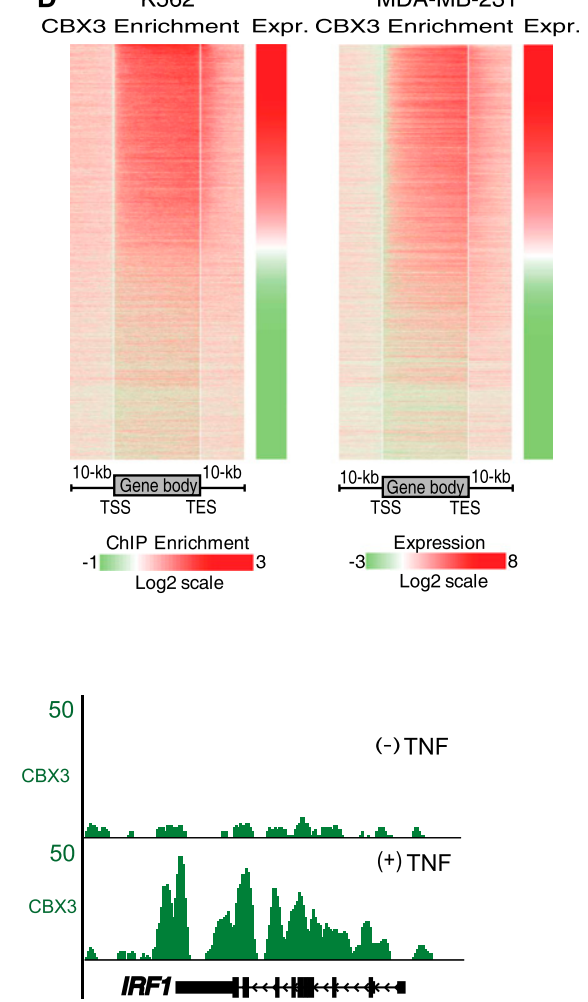

Figure 1. $C B X 3$ localization to gene bodies correlates with gene expression in multiple cell types. $(A)$ Distribution of ChIP-seq CBX3 targets between genic and nongenic regions in HCT116 cells. (B) Enrichment of $\mathrm{CBX} 3$ to top, middle, and bottom third expressed genes from $10 \mathrm{~kb}$ upstream to $10 \mathrm{~kb}$ downstream from gene body. Average enrichment in 500-bp bins every $1 \mathrm{~kb}$. Random region included as a control. (C) Venn diagram showing the overlap of ChIP-chip (NimbleGen arrays) CBX3 targets between K562, MDA-MB-231, and HCT116 cells. CBX3 target genes are called for each cell type based on whether they have $C B X 3$ peaks within their gene bodies. $(D)$ Log transformed expression levels, from Affymetrix arrays, for K562 and MDA-MB-231 genes clustered from highest to lowest expression (Expr.). Heatmap of CBX3 enrichment, by ChIP-chip, for clustered genes, from $10 \mathrm{~kb}$ upstream of the transcription start site (TSS) to $10 \mathrm{~kb}$ downstream from the transcription end site (TES). For each gene we divide the gene body into 50 equal divisions and use the $\log _{2}$ ratio of the nearest probe on the microarray to estimate the binding strength for every boundary position between these divisions. (E) ChIP-seq data visualized in UCSC browser snapshots showing CBX3 localization to the IL8 and IRF1 genes, in HCT116 cells treated \pm TNF for 30 min.

The top third expressed genes were enriched for CBX3 binding, whereas the bottom third unexpressed genes were not bound, with enrichment peaking at the 3 ' end of the gene body and then tapering off (Fig. 1B). We also performed ChIP-chip analysis with two other cell types, K562 (erythroid) and MDA-MB-231 (breast), using NimbleGen HD2 genome-wide tiling arrays. We found 7996 and 6241 CBX3-bound targets in K562 and MDA-MB-231 cells, respectively, 
compared with 8336 targets in HCT116 cells (Fig. 1C). CBX3 binding was likewise correlated with gene expression levels in K562 and MDA-MB231, demonstrating this is general phenomenon (Fig. 1D). For example, TIMP3, which has been implicated in breast cancer progression, was only expressed in MDA-MB-231 cells, where it is bound by CBX3 (Supplemental Fig. S1B). In fact, over $90 \%$ of CBX3 targets for all cell types tested are expressed in the corresponding cells. Our data expand upon an initial observation, demonstrating that $\mathrm{CBX} 3$ localization to the body of active genes is a genome-wide phenomenon. We therefore hypothesized that $\mathrm{CBX} 3$ is playing a functional role in gene regulation.

\section{Dynamic recruitment of $\mathrm{CBX} 3$}

The experiments described above demonstrate that CBX3 is present in the gene body of active genes in unstimulated cells. However, it is not clear whether CBX3 is recruited upon initiation of transcription or is present at genes prior to activation. To address this question, we performed ChIP-chip analysis of CBX3 localization before or after stimulation of K562, HCT116, or HeLa cells with TNF or IFNG. Using a custom ENCODE tiling microarray covering $\sim 1 \%$ of the human genome (Kim et al. $2005 \mathrm{a}$ ), we mapped the binding sites for CBX3 in HCT116 and HeLa cells both before and after IFNG and TNF treatment. Additionally, we determined gene expression profiles for each cell type under each condition by microarray experiments. We found that induction of transcription was correlated with a significant increase in CBX3 binding to the ENCODE arrays (Supplemental Fig. S1C; data not shown). Next, we performed ChIP-seq analysis on TNF-treated HCT116 cells and found that $\mathrm{CBX} 3$ was specifically and significantly recruited to many TNF-responsive genes (increased CBX3 binding was seen at 336 of 523 up-regulated transcripts). Representative browser shots showing CBX3 occupancy at the IL 8 and IRF1 loci, before or after TNF treatment, are shown (Fig. 1E).

\section{CBX3 interacts with elongating forms of RNA polymerase II}

It was previously reported that RNA polymerase II could be coimmunoprecipitated from nuclear extract (NE) with CBX3 (Vakoc et al. 2005). Indeed, CBX3 enrichment to gene bodies has been shown to be abrogated by treatment with the P-TEFb inhibitor DRB, which prevents RNA polymerase II elongation on active genes (Vakoc et al. 2005; J. Espinosa, unpubl.). We performed coimmunoprecipitation assays using HeLa extracts and antibodies against CBX3. The results demonstrate that CBX3 interacts with the phosphorylated forms of RNA polymerase II (Supplemental Fig. S1D). This result suggests that CBX3 localization to active genes could, at least in part, be mediated by its association with the elongating form of RNA polymerase II. However, we also note that CBX3 is not present at all active genes, suggesting that additional factors may affect CBX3 recruitment. Since CBX3 is known to bind to $\mathrm{H} 3 \mathrm{~K} 9 \mathrm{me} 2 / 3$ via its chromodomain, we first asked whether this could also be the mechanism for its localization to gene bodies. However, we were not able to detect significant $\mathrm{H} 3 \mathrm{~K} 9 \mathrm{me} 2 / 3$ at CBX3 target genes (data not shown). This is in agreement with HP1 and SU(VAR)3-9 localizing together at pericentric regions but independently at many other regions in Drosophila (Greil et al. 2003). Next, we tested the possibility that CBX3 could be binding to or stabilized by the H3K36me3 modification, since CBX3 binding was strongly correlated with histone H3K36me3 enrichment in multiple cell types (data not shown). Biotinylated histone $\mathrm{H} 3$ tail peptides with K9me3, K36me3, or no modification were incubated with purified CBX3 (Supplemental Fig. S1E). As expected, CBX3 binds with high affinity to $\mathrm{H} 3 \mathrm{~K} 9 \mathrm{me} 3$ peptides. However, no binding to the H3K36me3 modified peptide was detected.

\section{CBX3 positively regulates transcript levels of its target genes}

The data presented thus far suggest that $\mathrm{CBX} 3$ is recruited to genes upon activation and could therefore be playing a role in gene regulation. However, it is unclear if $\mathrm{CBX} 3$ is acting to increase or decrease transcriptional output at its target loci. To address this issue, we utilized an HCT116 cell line stably expressing a CBX3specific shRNA construct (KD HCT116). CBX3 knockdown was validated by RT-qPCR and Western blot analyses (Supplemental Fig. S2A). In all subsequent experiments, the data presented as KD HCT116 cells is from analysis of clone 10 (clone 8 was also analyzed with similar results to clone 10; data not shown). Gene expression levels in wild-type (WT) and KD HCT116 cells were analyzed by Affymetrix exon arrays and RNA-seq, yielding comparable results. To determine the effect of CBX3 depletion on transcription, we calculated the expression of all genes in WT and KD HCT116 cells using the RNA-seq data set. Genes were grouped as those either bound or unbound by CBX3 in WT cells, and then expression profiles of these gene groups were compared in WT and KD cells. CBX3-bound genes are expressed at much higher levels than unbound targets, red and blue lines versus green and black lines (Fig. 2A). Notably, there was a subset of genes unbound by CBX3 but still significantly expressed; these will be discussed later. Surprisingly, despite widespread CBX3 binding to actively transcribed genes, we did not observe large-scale alteration of transcript levels; compare red to blue lines and green to black (Fig. 2A). More detailed analysis revealed that a small number of genes are in fact differentially expressed (367 down-regulated and 340 up-regulated, by more than twofold) in the KD cells. Genes that were downregulated upon loss of CBX3 were enriched for CBX3 binding in WT HCT116 cells when compared to genes up-regulated (Fig. 2B). The correlation between loss of CBX3 binding and a decrease in gene expression suggests that $\mathrm{CBX} 3$ can positively regulate transcription. Results were validated for several genes, including $E H F$ and GPR110, by RT-qPCR and RNA-seq analysis in WT and KD cells (Fig. 2C; Supplemental Fig. S2B,C). Of interest, CBX3 is enriched across gene clusters, such as the $K L K$ (kallikrein serine proteases) family on chromosome 19 whose up-regulation, like that of CBX3, has been implicated in carcinogenesis. Loss of CBX3 resulted in a coordinated down-regulation of the KLK genes (Fig. 2D).

We analyzed the expression levels of several TNF-responsive genes in both WT and KD HCT116 cells by RT-qPCR and/or RNAseq. As depicted in Figure 2E and Supplemental Figure S3A, multiple TNF-responsive genes are also negatively affected by loss of CBX3. We observed that expression of a subset of TNF-responsive genes, such as NFKB1 and ZC3H12C, was not altered in KD cells. However, these genes possess only background levels of CBX3 occupancy that does not increase upon gene activation (Supplemental Fig. S3B; data not shown).

Loss of CBX3 caused only mild transcriptional defects for a subset of genes. This suggests that the primary function of CBX3 binding to gene bodies may not be to directly regulate transcription levels per se. We therefore considered the possibility that CBX3 was influencing multiple facets of gene regulation.

\section{CBX3 preferentially associates with exons in multi-exonic genes}

Further analysis of CBX3 targets revealed that the bound genes were significantly longer than unbound genes $(27227$ bp versus 
A

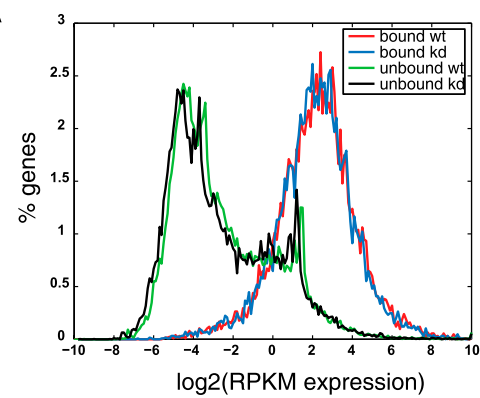

B

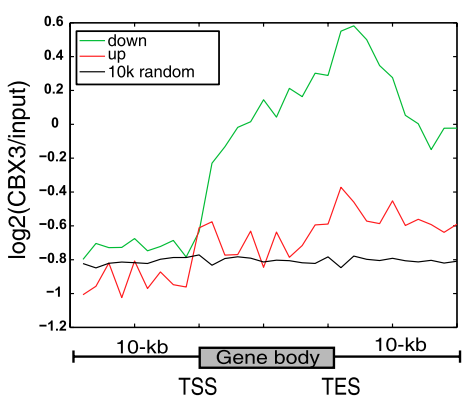

C
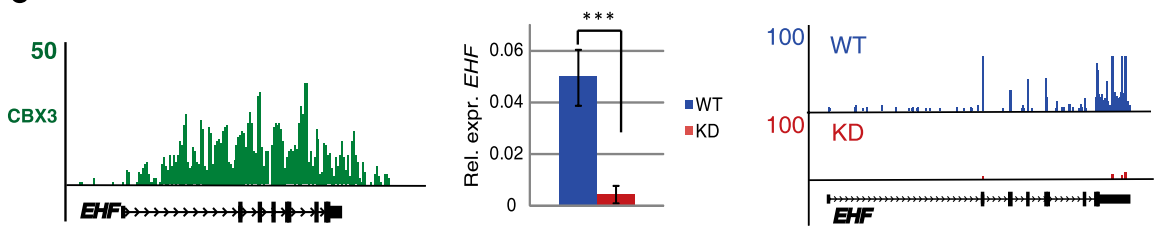

D

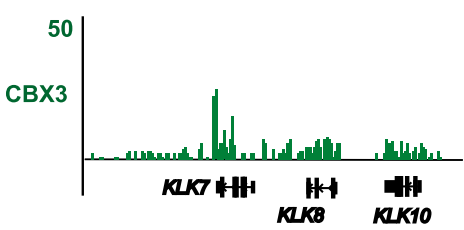

E

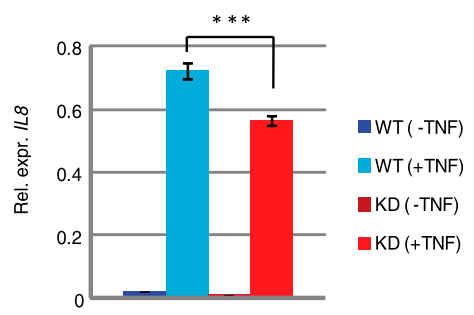

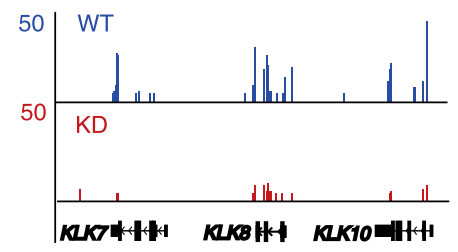

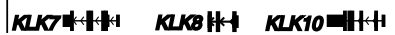

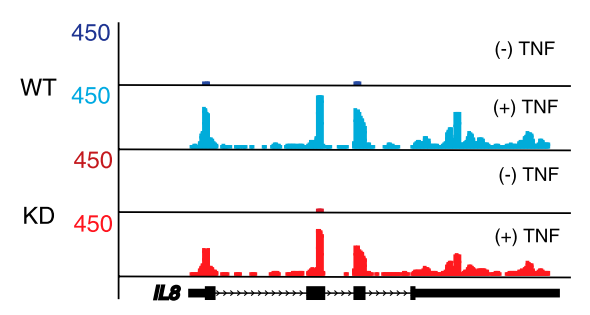

Figure 2. $C B X 3$ target genes are down-regulated in KD HCT116 cells. (A) Comparison of $\log _{2}$ (RPKM expression) profiles for genes in KD and WT cells, grouped as either bound or unbound by CBX3 (in WT cells). Bound WT red line, bound KD blue line, unbound WT green line, and unbound KD black line. (B) CBX3 enrichment, from WT cells, for genes up- or down-regulated in CBX3 KD HCT116 cells. $\log _{2}$ CBX3 (IP/input), from CBX3 ChIP-seq in WT HCT116 cells, binned as in Figure 1B with random regions as a control. ( $C$, left) ChIP-seq UCSC Genome Browser snapshot of CBX3 enrichment at the EHF gene. (Middle) RT-qPCR analysis of EHF expression in WT and KD HCT116 cells. (Right) RNAseq UCSC Genome Browser snapshot of EHF expression level in WT and KD cells. ( $D$, left) CBX3 binding. (Right) RNA-seq browser shot (as in $C$ ) for KLK gene cluster. (E, left) RT-qPCR analysis of TNFresponsive CBX3 target IL8 in KD and WT HCT116 cells treated \pm TNF for $30 \mathrm{~min}$. (Right) UCSC Genome Browser snapshot of RNA-seq IL8 expression. RT-qPCR expression levels normalized to $G A P D H$ and are the average of three biological replicate experiments. Error bars calculated as the standard deviation between replicates. $\left.{ }^{* * *}\right) P \leq 0.001$.

14161 bp; $P<4.77 \times 10^{-283}$, Wilcoxon rank sum test) (Fig. 3A). Additionally, CBX3-bound genes have a median exon number of 10 , whereas unbound genes have a median of five $(P$-value $1 \times$ $10^{-300}$, Wilcoxon rank sun test) (Fig. 3B). Next we calculated CBX3 occupancy at genes grouped by exon number, from one to $21+$. CBX3 binding clearly favors multi-exon genes over single-exon genes (Fig. 3C; Supplemental Fig. S4A). In addition, we calculated expression levels of genes grouped by exon number (Fig. 3D; Supplemental Fig. S4A). Overlay of these two graphs revealed that CBX3 binding correlated with expression level of genes, for the most part,

when grouped by exon number. Interestingly, in contrast to all other groups, single-exon genes were highly expressed despite a lack of CBX3 enrichment (Supplemental Fig. S4A). These data suggest that expression of longer, multi-exon genes is more dependent on CBX3 binding than that of single-exon genes. In support of this idea, the mean exon number for the group of expressed unbound genes, mentioned in Figure $2 \mathrm{~A}$, is one. Next we created a heatmap of average CBX3 enrichment at the $5^{\prime}$ of exons (and $\pm 2.5 \mathrm{~kb}$ upstream and downstream) ranked from low (black bar), to middle (green bar), and to high (red bar) expression. We observed that CBX3 is enriched at exon boundaries (Fig. 3E). In addition, we plotted CBX3 enrichment (tag counts per kilo base) at exons versus introns for all genes and those with high, medium, or low CBX3 binding (Supplemental Fig. S4B). While CBX3 binds to introns, it is clearly enriched in exons. Increased CBX3 enrichment is correlated with increased exon expression levels (Fig. 3E,F). Collectively, these data suggest that CBX3 could be playing a role in RNA processing.

Recently, CBX3 has been implicated in the regulation of alternative splicing with CBX3 enriched at alternatively spliced exons of CD44 (Saint-Andre et al. 2011). In contrast, CBX3 is evenly recruited to CD44 in HCT116 cells, and there was no change in splicing of this gene between WT and KD cells (data not shown). To further investigate, we calculated CBX3 enrichment (RPKM value) for exons included in mature transcripts (spliced in) versus those not included (spliced out) in HCT116 cells. We observed that CBX3 enrichment is not significantly different for alternatively spliced or constitutive exons (Supplemental Fig. S4C). Additionally, loss of CBX3 did not decrease the inclusion of 219 alternatively spliced exons examined. Intriguingly, we found that loss of $\mathrm{CBX} 3$ results in an increased inclusion of exons usually spliced out (Fig. 3F). The preference for exon-rich genes and enrichment at exons coupled with increased exon inclusion in the absence of CBX3 led us to consider the possibility that CBX3 could be regulating RNA processing generally but not alternative splicing specifically in our system.

\section{Loss of function of CBX3 causes a disruption in splicing of target genes}

To test whether CBX3 indeed participates in RNA processing, we first examined the IL8 gene. We designed primer pairs spanning each exon-intron junction as well as one exon-exon junction. 
A

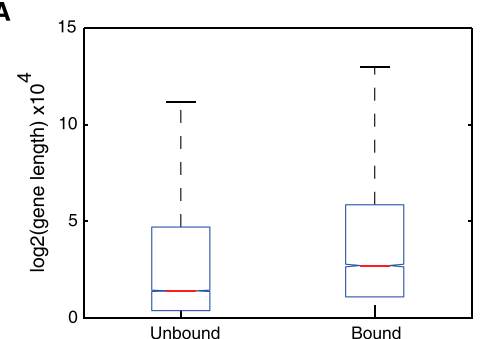

C
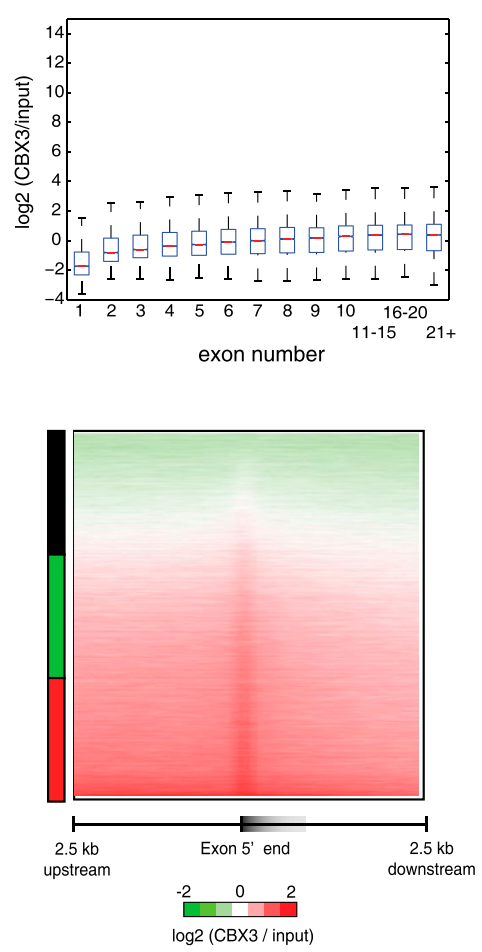

B

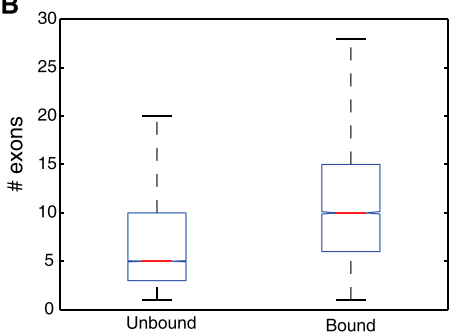

D

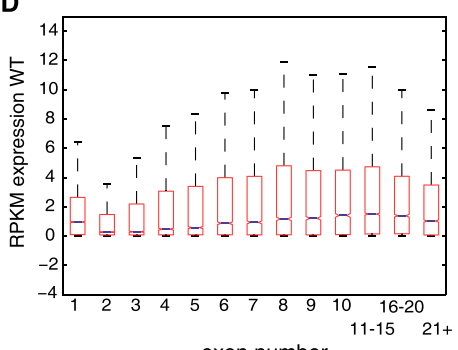

exon number

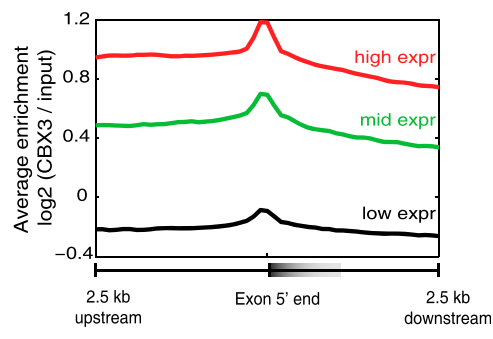

G

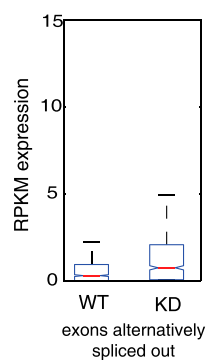

Figure 3. $C B X 3$ binds to longer, exon-rich genes. $(A)$ Box plot of $\log _{2}$ (gene length) of $C B X 3$ bound or unbound genes in WT HCT116 cells. $P=4.77 \times 10^{-283}$. (B) Box plot of median exon number for $\mathrm{CBX} 3$ bound and unbound genes. $P=1 \times 10^{-300}$. (C) Box plot of $C B X 3$ enrichment, $\log _{2}$ (CBX3/input), for genes grouped by exon number from 1 to $21+$. (D) Box plot showing RPKM expression, in WT cells, of genes grouped by exon number from 1 to $21+$. (E) Heatmap of CBX3 enrichment $2.5 \mathrm{~kb}$ upstream of and downstream from TSS distal exons in WT HCT116 cells. Signal normalized to input and targets clustered by exon expression from lowest to highest. $(F)$ Average CBX3 enrichment at high (red), middle (mid-green), and low (black) third expressed exons. $(G)$ Comparison of RPKM expression for alternatively spliced exons (alt out) in WT and KD cells. P-value for "alt out" exon in WT versus KD $2.771 \times$ $10^{-15}$. For box plots, the median is represented by the center line; the edges of the box represent the 25th and 75th percentiles; and the whiskers extend to non-outlier extreme data points. P-values obtained using the Wilcoxon rank sum test.

Exon-intron spanning primers will amplify unspliced transcripts, whereas exon-exon spanning primers only measure spliced transcripts. This approach allowed us to compare the expression level of spliced and unspliced IL8 mRNAs in WT and CBX3 KD HCT116 cells. We calculated the ratio of intron (exon-intron junction) to exon (exon-exon junction) expression across the IL 8 gene for WT and $\mathrm{KD}$ cells (Fig. 4A, left). In addition, the fold change of intron

expression, or the level of unspliced transcript, in WT to KD cells was analyzed (Fig. 4A, right). We detected a significant increase in intron inclusion in KD HCT116 cells at every splice junction across the IL8 gene $(P<0.05, t$-test $)$. In fact, loss of CBX3 leads to a two- to fivefold increase in unspliced IL 8 transcripts in the $\mathrm{KD}$ HCT116 cells.

To ascertain if this was a common effect of CBX3 loss, we analyzed intron inclusion in several additional TNFresponsive genes, including $I L 1 A, E H D 1$, and $L T B$ (Fig. 4B; Supplemental Fig. S5A). As observed for $I L 8$, loss of CBX3 resulted in an increase in unspliced transcripts for all CBX3 target genes tested. The correlation between loss of CBX3 and increase in intron inclusion was also seen for the CBX3-responsive gene HOXA9 in unstimulatedcells (Fig. 4C). However, no increase in unspliced transcripts was observed for genes not bound by CBX3, such as NFKB1 and ZC3H12C (Fig. 4D; Supplemental Fig. S5B); these genes show no disruption of RNA processing. Therefore, the RNA processing defect we observe correlates with a decrease in CBX3 binding.

\section{Loss of $\mathrm{CBX} 3$ results in global RNA processing defect}

To further investigate the role of CBX3 in RNA processing, we performed genomewide analysis of both poly-A and nonpoly-A transcript levels from WT and KD HCT116 cells. Total RNA was isolated from WT and KD HCT116 cells and subjected to high-throughput sequencing analysis after depletion of ribosomal RNA. Exonic and intronic expression was measured using this procedure for all UCSC genes with a detectable transcription (RPKM $\geq 0.5$, which is approximately the median RPKM of the samples). We quantified the fraction of intronic expression as intron RPKM/exon RPKM for each gene and found 1037 transcripts that display a marked increase in intronic expression in the KD compared with WT cells (KD/WT $\geq$ 2). This increase in intron inclusion for genes in KD cells could also be observed in the raw RNA-seq data visualized in the UCSC Genome Browser (Fig. 5A). Next we ascertained whether loss of CBX3 binding correlated with an increase in unspliced transcripts. We detected significant enrichment of CBX3 at genes with increased unspliced transcripts (Fig. 5B). Analysis of a replicate RNA-seq data set produced similar results, with significant overlap of genes found to have increased intronic inclusion $\left(P<1 \times 10^{-16}\right)$ and CBX3 enrichment (Supplemental Fig. S6). Our data demonstrate that genes bound by CBX3 in WT cells

\section{Genome Research www.genome.org}


A

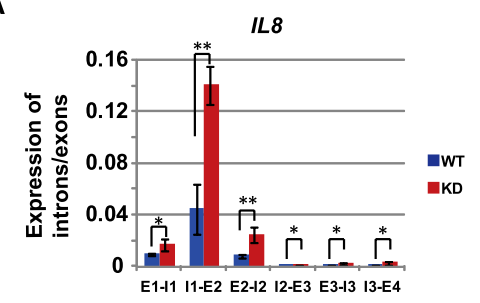

B
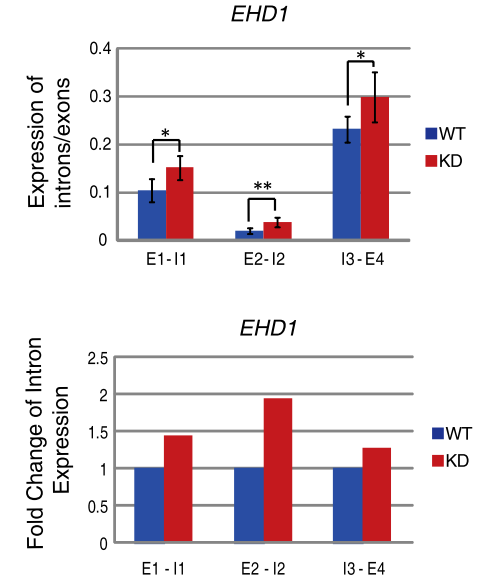

C

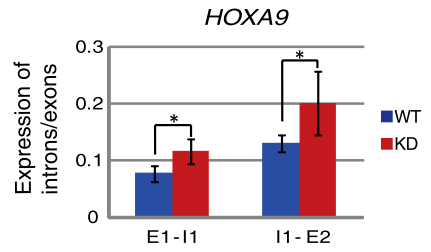

IL8

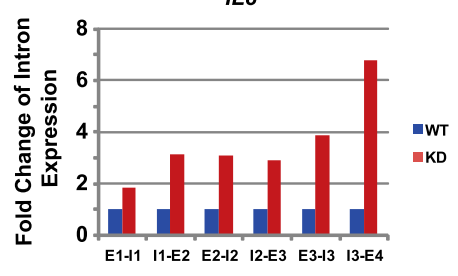

$\angle T B$

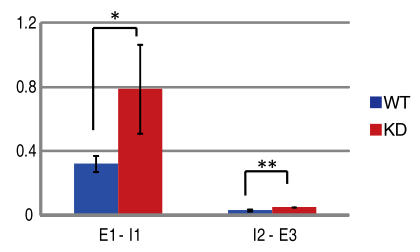

$L T B$

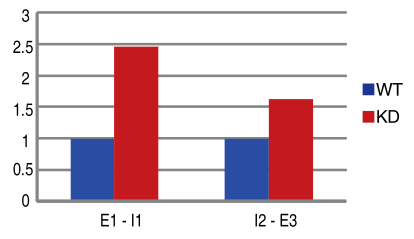

D

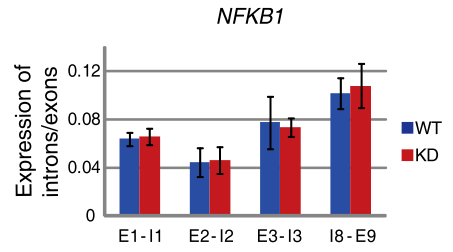

Figure 4. Depletion of $C B X 3$ causes a decrease in splicing only at $C B X 3$ target genes. $(A-D) R T-q P C R$ analysis of intron/exon expression ratios for intron-exon boundaries across candidate genes. The ratio was calculated by dividing intron expression, from intron-exon junction primer set, by exon expression, from intron spanning primer set. $(A, B, D)$ RNA isolated from WT or KD HCT116 cells treated with TNF for $30 \mathrm{~min}$. (C) RNA isolated from untreated WT and KD cells. (A, left) Intron/exon expression ratios for all intron-exon boundaries across the IL8 gene. (Right) Fold change of intron/exon expression over WT for left panel. ( $B$, top) Intron/exon expression ratios for TNF-responsive, CBX3 target genes EHD1 and LTB. (Bottom) Fold change of intron expression over WT. (C) Intron/exon expression ratios for HOXA9. (D) Intron/exon expression ratio for NFKB1, a TNF-responsive, non-CBX3 target gene. Expression levels of all samples were normalized to GAPDH and are the average of at least three biological replicate experiments. Error bars calculated as the standard deviation between replicates. $\left(^{*}\right) P \leq 0.05,\left(^{* *}\right) P \leq 0.01$.

display an increase in splicing defects upon depletion of CBX3. Of the 367 genes down-regulated by the loss of CBX3, 85 also have an increase in unspliced transcripts. It could be hypothesized that the decrease in transcript level is due to degradation of unspliced transcripts. However, the significant number of genes with either splicing defects or a decrease in transcript level but not both suggests that separate mechanisms of action could be at play.

\section{CBX3 influences recruitment of splicing factors to actively transcribed genes}

The spliceosome is a large multi-subunit complex that is assembled in a highly ordered and cooperative manner to the RNA transcript. SR (serine and arginine-rich) proteins also bind to Ser2phosphorylated RNA polymerase II and could play a role in recruiting splicing factors to the elongating polymerase (Shepard and Hertel 2009; Lenasi and Barboric 2010; Licatalosi and Darnell 2010). Since CBX3 binds to RNA polymerase II, we posited that CBX3 could also be playing a role in recruitment of the splicing complexes or regulators. Therefore, we performed ChIP to analyze splicing factor recruitment to a series of candidate genes in WT and KD cells. Interestingly, we discovered that SNRNP70 (U1-70K, 70K protein subunit of U1) and SRSF1 (SF2/ASF, SR family protein) recruitment, to IL1A, is decreased upon CBX3 loss (Fig. 6A). This was not due to a decrease in the expression level of splicing factors in the KD cells, as the levels were comparable to those seen for WT HCT116 by Western blot (Supplemental Fig. S7A). Notably, this phenomenon was limited to active CBX3-bound genes where we observed splicing defects (e.g., IL1A) and not control, non-CBX3 targets, such as NFKB1, that do not have splicing defects (Fig. 6B). Therefore, recruitment or stabilization of the spliceosome factors tested appears to be dependent upon CBX3 localization to the gene in question.

\section{Discussion}

Heterochromatin protein 1 has been implicated in a diverse array of cellular processes, including heterochromatin formation, gene silencing, DNA damage repair, telomere stability, and RNAimediated silencing (Hediger and Gasser 2006; Kwon and Workman 2008; Dinant and Luijsterburg 2009; Zeng et al. 2010). Here, we provide evidence that in human cells CBX3 supports transcription and efficient splicing. We demonstrate that CBX3 is localized to the gene body of the most actively transcribed genes. We observe that CBX3 preferentially associates with exons in multiple-exon genes. Knockdown of CBX3 expression results in down-regulation of a subset of target genes and significant accumulation of unspliced transcripts from greater than 1000 transcripts. Depletion of CBX3 also causes a defect in recruitment of splicing factors SNRNP70 and SRSF1 to the CBX3 target gene IL1A. This is suggestive of a role for CBX3 in RNA processing through recruitment or stabilization of spliceosome components to at least a subset of target genes.

Heterochromatin protein 1 family proteins are conserved from yeast to humans and are widely accepted as critical components of silenced/repressed chromatin (Singh and Georgatos 2002; Dillon 2004; Maison and Almouzni 2004; Huisinga et al. 2006; Lomberk et al. 2006; Motamedi et al. 2008). However, in Drosophila both SU(VAR)205 and HP1c are also found at active loci (Fanti et al. 2003; Greil et al. 2003; de Wit et al. 2007). In mammalian cells, CBX5 and -1 are predominantly heterochromatic but are known to 
A
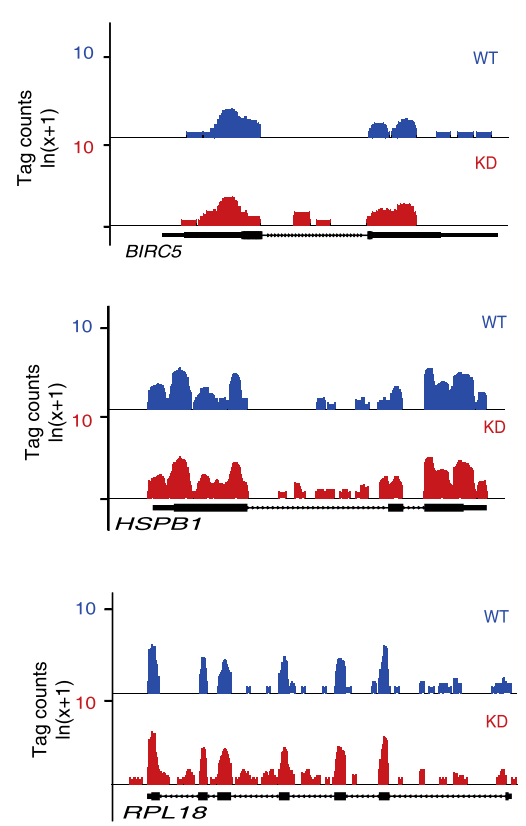

B

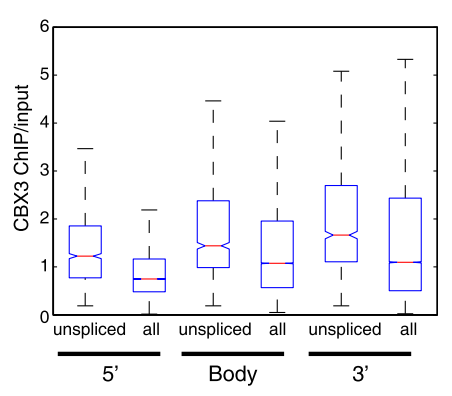

Furthermore, we observe that CBX3 recruitment is inducible by extra-cellular signaling.

It has been posited that CBX3 may act to attenuate the transcription output of its target genes (Hiragami and Festenstein 2005; Vakoc et al. 2005). Supporting this hypothesis, it was demonstrated in Drosophila that genes bound by SU(VAR)205 are expressed at lower levels (de Wit et al. 2005). We utilized a HCT116 CBX3 knockdown cell line to probe the effect of CBX3 on gene expression in human cells. Knockdown of CBX3 only modestly affected global transcript level, with 367 genes being down-regulated and 340 up-regulated (by more than twofold). Interestingly, only down-regulated genes were bound by CBX3, suggesting a positive role for CBX3 regulating gene expression. It should be noted, however, that the number of target genes affected by CBX3 depletion is small in comparison to the total number of CBX3 target genes. While we cannot completely exclude the role of residual CBX3 in the KD HCT116 cells, this result led us to hypothesize that CBX3 could be playing another role aside from transcriptional regulation. Further analysis of targets revealed that CBX3 preferentially binds to longer, exon-rich genes. Interestingly,

be recruited to specific promoters to silence transcription (Feldman et al. 2006; Yahi et al. 2008). In contrast, CBX3 was found to be more widely associated with euchromatin and is recruited to silence promoters by a variety of factors (Ogawa et al. 2002; Vicent et al. 2006; du Chene et al. 2007; Liu et al. 2010). More recently, CBX3 was also found localized to active genes in a number studies (Vakoc et al. 2005; Smallwood et al. 2007; Mateescu et al. 2008).This discovery sparked much debate and speculation about the role of a heterochromatin factor in this context. Most recently, a role for CBX3 in alternative splicing, at a select group of genes, has been suggested (Saint-Andre et al. 2011). However, to date, no examination of CBX3 localization or function genome-wide has been performed. Our study represents the first high-resolution genome-wide analysis of a mammalian heterochromatin family member. We found that CBX3 is predominantly localized to the gene body of active genes in all the cell types examined. While CBX3 binding is usually limited to between the transcription start and termination sites, there are examples of large domains of CBX3 that encompass multiple genes including the HOXA and $K L K$ loci. CBX3 binding is strongly correlated with the level of gene expression.

A

B
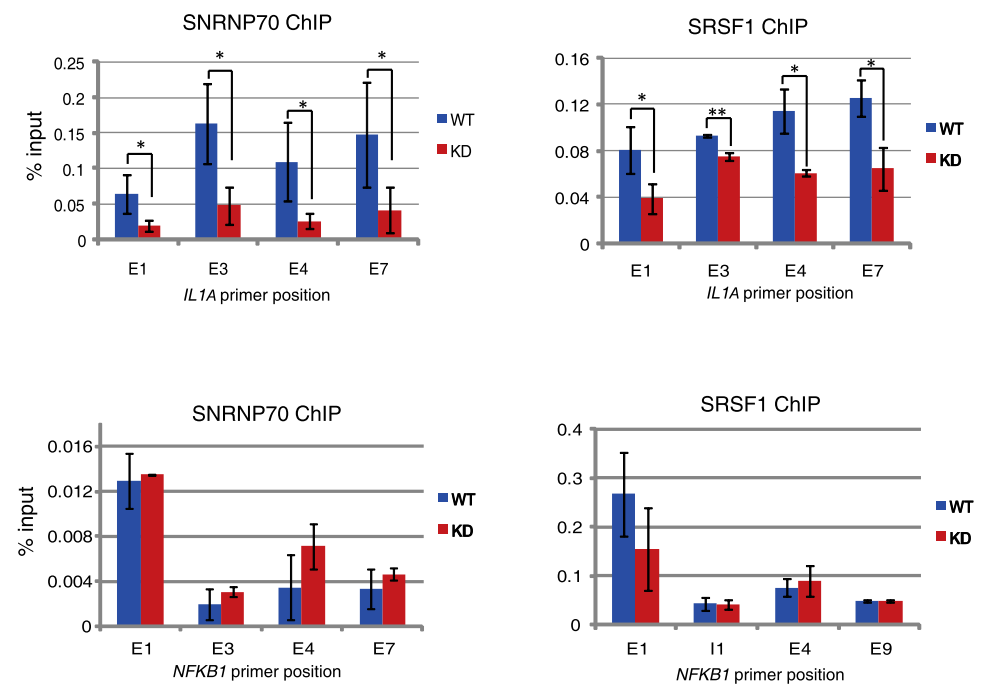

Figure 6. $\mathrm{CBX} 3$ binds preferentially to exons and influences recruitment of splicing factors. $(A, B)$ ChIP-qPCR for SNRNP70 and SRSF1 splicing factor binding to IL1A and NFKB genes in WT and KD HCT116 cells treated for 30 min with TNF. IPs are represented as percentage input and are the average of at least three biological replicate experiments. Error bars calculated as the standard deviation between replicates. $\left(^{*}\right) P \leq 0.05,\left({ }^{* *}\right) P \leq 0.01$.

\section{Genome Research www.genome.org}


in CBX3 target transcripts. Importantly, this is a genome-wide phenomenon, and genes that exhibit splicing defects in the absence of CBX3 are bound by CBX3 in WT cells. Therefore, decreased transcript levels of CBX3 target genes observed upon CBX3 depletion in HCT116 cells may result from their increased degradation due to improper splicing or from a direct effect of CBX3 on transcriptional output.

Saint-Andre and colleagues (Saint-Andre et al. 2011) suggest a role for CBX3 in alternative splicing of CD44 in HeLa cells, whereby depletion of CBX3 led to a decreased inclusion of variant exons. Our study takes a wider unbiased approach to determine the effect of CBX3 depletion on transcriptional and splicing processes genome-wide. Therefore, in contrast to the previous study, we observed that loss of CBX3 caused a general increase in intron inclusion and loss of splicing and therefore resulted in accumulation of unspliced RNAs. However, GO analysis revealed that many of the unspliced transcripts that accumulate in KD cells are known to be alternatively spliced. It is therefore possible that CBX3 is playing multiple overlapping roles in splicing regulation.

It has been previously suggested in Drosophila that SU(VAR)205 could function to stabilize RNA transcripts (Piacentini et al. 2009). We performed RNA stability assays to determine if CBX3 affects splicing via RNA stabilization. HCT116 cells were treated with $\alpha$-amanitin for $0-120 \mathrm{~min}$, and the RNA was isolated at various time points. Levels of $H O X A 9, E Z R$, and EHF spliced and unspliced transcripts were determined by RT-qPCR using multiple independent primer sets (Supplemental Fig. S7B-D). A decrease in splicing of these transcripts was observed in response to CBX3 knockdown in HCT116 cells. We could detect no difference in RNA stability between WT and KD cells; therefore, CBX3 must be functioning via a different mechanism in human cells.

Most notably, we demonstrated that in human cells depleted of CBX3, recruitment of the RNA splicing factors SNRNP70 and SRSF1 was decreased significantly to IL1A. This loss of splicing factor recruitment was specific to CBX3 target genes. Levels of SNRNP70 and SRSF1 were unaffected at genes not bound by CBX3, such as NFKB1. While these data do not provide a direct role for $\mathrm{CBX} 3$ in splicing, the correlation between CBX3 occupancy and splicing defects does implicate CBX3 in the process. RNA polymerase II plays a central role in the coupling of transcription, and splicing Ser-2 of the RNA polymerase II C-terminal domain (CTD) is phosphorylated during elongation, creating a binding platform for recruitment of splicing factors to the RNA template (Allemand et al. 2008; Tilgner and Guigo 2010). CBX3 also interacts with phosphorylated RNA polymerase II, raising the possibility that the CTD of polymerase could act as a platform to coordinate the action of CBX3 and components of the splicing machinery. The splicing factor SRSF1 binds to Ser-2 phosphorylated RNAP II, and this interaction aids recruitment of U1 and U2 snRNPs (Allemand et al. 2008; Moore and Proudfoot 2009; Perales and Bentley 2009). We, and others, observe that $\mathrm{CBX} 3$ also associates with the elongating form of RNA polymerase II, thus providing a mechanism by which CBX3 may influence the recruitment and/or activity of splicing factors.

Recently, Black and colleagues (Black et al. 2010) demonstrated that CBX3, along with a histone demethylase, plays a role in cell cycle regulation in Caenorhabditis elegans and human cells. Additionally, CBX3 has been implicated in controlling levels of primordial germ cells (PGCs) in mouse embryos via cell cycle regulation and apoptosis (Abe et al. 2011). Overexpression of CBX3 has been detected in multiple cancer cell lines and is thought to play a role in tumorigenesis (Takanashi et al. 2009). We performed
GO term analysis of genes either down-regulated or with decreased RNA processing upon depletion of CBX3. We determined that $\mathrm{CBX} 3$ is responsible for regulating many genes involved in cell cycle progression, including CDK11A, CDC25C, DDX11, ATM, and CCNE1. In addition, loss of CBX3 altered expression of PIM1, $C A V 2$, and CCNE1, all of which are thought to be involved in cancer progression.

Collectively, this study extends the previous observation that CBX3 binds to gene bodies by demonstrating that this is a genomewide phenomenon. In addition, binding correlates with gene activity, in multiple cell types, and depletion of CBX3 leads to a decrease in transcription for a subset of target genes. Importantly, this study begins to shed light on another role of CBX3 in this context: aiding in efficient processing potentially via splicing factor recruitment. Our data provide evidence that CBX3 may play a role in a variety of cellular processes through regulation of gene expression and splicing.

\section{Methods}

\section{Generation of stable CBX3 knockdown HCT116 cells}

The CBX3 shRNA used in this study was designed using the pSicoOligomaker 1.5 algorithm (Jacks Laboratory, MIT). Oligonucleotides encoding the shRNA were annealed and cloned into the pLL3.7 lentiviral expression vector according to the Jacks Laboratory's protocol. Oligonucleotide sequences are as follows: forward oligo, 5'-TGAGGCAGAGCCTGAAGAATTTCAAGAGAATTC TTCAGGCTCTGCCTCTTTTTTC-3'; reverse oligo, 5'-TCGAGA AAAAAGAGGCAGAGCCTGAAGAATTCTCTTGAAATTCTTCAGG CTCTGCCTCA-3'. Lentivirus production and transduction of HCT116 cells were carried out using protocols established in the Jacks Laboratory. Individual HCT116 cell clones expressing the CBX3 shRNA were isolated by limiting dilution, and the degree of CBX3 depletion in individual clones was ascertained by Western blot analysis. Clones 8 and 10 were selected for further study.

\section{Cell culture}

K562, MDA-MB-231, and HCT116 cells were grown in Iscove's Modified Dulbecco's, Leibowitz, and McCoys media, respectively, all supplemented with 10\% FBS and 1\% pen-strep. Cells were treated with either $10 \mathrm{ng} / \mathrm{mL}$ TNF for 30-60 min or IFNG for 30 min. For ChIP, cells were crosslinked with $1 \%$ formaldehyde for 15 min at $37^{\circ} \mathrm{C}$ and then harvested as previously described (Li et al. 2003; Kim et al. 2005b). For expression analysis, RNA was isolated with TRIzol as per manufacturer's instructions.

\section{Chromatin immunoprecipitation}

ChIP was performed as previously described (Li et al. 2003; Kim et al. 2005a). Briefly, $2 \mu \mathrm{g}$ of specific antibodies was bound to Dynal magnetic secondary beads for $6 \mathrm{~h}$. After washing, $200 \mu \mathrm{g}$ of sonicated chromatin was incubated with the bead-bound antibody overnight. Beads were washed, and enriched DNA was isolated. ChIP DNA was then analyzed by hybridization either to custommade DNA microarrays covering the ENCODE regions (Li et al. 2003; Kim et al. 2005a) or to oligonucleotide microarray arrays covering the entire human genome (Roche NimbleGen) (Kim et al. 2005b). The ChIP DNA was also sequenced after adapter ligation and amplification steps (Johnson et al. 2007), as previously detailed. For qPCR analysis, samples and inputs were diluted eightfold, and then enrichment of DNA was analyzed with primers specific to candidate genes (see Supplemental Materials). 


\section{ChIP-chip analysis}

Enriched DNA from ChIP experiments were prepped for hybridization to Roche NimbleGen microarrays as previously described (Kim et al. 2005b). Briefly, $1 \mu \mathrm{g}$ each of immunoprecipitated or input genomic LM-PCR DNA was annealed with Cy5 and Cy3 endlabeled random prime nonamer oligonucleotides. Annealed DNA was then incubated with DNA polymerase Klenow fragment and dNTPs for $2 \mathrm{~h}$ at $37^{\circ} \mathrm{C}$. The labeled samples were isolated by ethanol precipitation. Equal amounts of Cy5-labeled immunoprecipitated DNA and Cy3-labeled input DNA were mixed and hybridized to NimbleGen HD2 economy tiling arrays (hg18 NimbleGen-Roche) using the MAUI Hybridization Station (BioMicro Systems) for 16$20 \mathrm{~h}$ at $42^{\circ} \mathrm{C}$. The hybridized slides were washed twice in Wash buffer $1(0.2 \times$ SSC, $0.2 \%$ SDS, and $0.1 \mathrm{mM} \mathrm{DTT})$ and once each in buffer $2(0.2 \times$ SSC and $0.1 \mathrm{mM} \mathrm{DTT})$ and buffer $3(0.05 \%$ SSC and $0.1 \mathrm{mM}$ DTT) and then dried. The arrays were scanned on an Axon GenePix 4000B scanner (Axon Instruments) at $532 \mathrm{~nm}$ for Cy3 and $635 \mathrm{~nm}$ for Cy5. We used MA2C package (Song et al. 2007) to do data normalization with default parameters (Robust $\mathrm{C}=2$ ) and peak calling.

\section{ChIP-seq analysis}

ChIP-seq reads were mapped by the Eland to hg18, keeping only uniquely mapping genes and discarding all but one of clonal reads (the number of monoclonal reads for each sample is included in Supplemental Table S4). Blocks of CBX3 enrichment over input were identified as previously described (Hawkins et al. 2010). To compute ChIP enrichment relative to input, we computed the RPKM of ChIP and input for each of the regions and divided ChIP RPKM by input RPKM. To avoid division by zero, a pseudo count of 1 was added to each region before division. CBX3-bound genes were defined as those having $\log _{2}(\mathrm{CBX} 3 \mathrm{RPKM} /$ input RPKM $) \geq 1$ and unbound genes $\log _{2}(\mathrm{CBX} 3 \mathrm{RPKM} /$ input RPKM $) \leq 0$. Up/downregulated genes were defined as those having median level of expression in either WT or KD cells and that exhibit at least a twofold difference in expression. For exon enrichment, the RPKM of ChIP and input for 100-bp bins around exon 5' ends was calculated then and divided ChIP RPKM by input RPKM. Cassette exons were defined by the UCSC "knownalt" table from the alt events track.

\section{CBX3 coimmunoprecipitation}

Four micrograms of CBX3 antibody (Millipore 05-690) or R-IgG was incubated with $20 \mu \mathrm{L}$ of Protein G beads in $1 \times \mathrm{PBS} / 5 \mathrm{mg} / \mathrm{mL}$ BSA for $2 \mathrm{~h}$ at $4^{\circ} \mathrm{C}$. Unbound antibody was removed by washing with $1 \times \mathrm{PBS} / 5 \mathrm{mg} / \mathrm{mL}$ BSA. Antibody-bound beads were incubated with $6 \mathrm{mg}$ of nuclear or nuclear pellet extract for $4 \mathrm{~h}$ at $4^{\circ} \mathrm{C}$. Unbound factors were removed by washing three times with $300 \mathrm{mM}$ Buffer D (300 mM KCL, $20 \mathrm{mM}$ HEPES at $\mathrm{pH}$ 8.0, $0.1 \mathrm{mM}$ EDTA, $20 \%$ glycerol) and once with $100 \mathrm{mM}$ Buffer D. Beads were boiled in $50 \mu \mathrm{L}$ of SDS loading dye for $10 \mathrm{~min}$ prior to SDS-page gel electrophoresis. Factors bound to CBX3 were analyzed by Western blot.

\section{GST-CBX3 purification}

CBX3 protein and GST-CBX3 beads were purified as previously detailed (Vassallo and Tanese 2002; Smallwood et al. 2007). GSTCBX3 proteins were purified by expression in bacteria and enrichment on glutathione columns. Proteins were released from the GST tag and beads by thrombin cleavage. The concentration of CBX3 or GST-CBX3 was analyzed by SDS-PAGE and Coomassie staining.

\section{Peptide pulldowns}

Interaction of soluble nuclear factors with immobilized peptides was performed as previously described (Wysocka et al. 2005; Sims et al. 2006). In short, $5 \mu \mathrm{g}$ of biotin tagged histone tail peptide was bound to $25 \mu \mathrm{L}$ of streptavidin coated beads for $15 \mathrm{~min}$ at room temperature in $5 \mathrm{mM}$ Tris (pH 8.0), $0.5 \mathrm{mM}$ EDTA, and $1 \mathrm{M} \mathrm{NaCl}$. Unbound peptides were washed away by washing three times with $100 \mathrm{mM}$ Buffer D. Beads were incubated with $300 \mathrm{ng}-1 \mu \mathrm{g}$ of purified CBX3, in $300 \mu \mathrm{L}$ of $100 \mathrm{mM}$ Buffer D, for $2 \mathrm{~h}$ at $4^{\circ} \mathrm{C}$. Unbound factors were removed by three washes with $300 \mathrm{mM}$ Buffer D. CBX3 associated with the peptides was eluted by boiling in $2 \%$ SDS and analyzed by SDS-page electrophoresis and Western blotting.

\section{RT-qPCR}

Total RNA was isolated by TRIzol extraction, DNase 1 treated, and then subjected to cDNA synthesis using Invitrogen Super script kit as per the manufacturer's instructions. qPCR analysis was performed using $0.5 \mu \mathrm{L}$ of cDNA as template in $20 \mu \mathrm{L}$ reaction volumes using Sybr green master mix from Roche. All results were normalized to GAPDH expression. A no-RT control was included in each experiment to ensure results were not from contaminating DNA. Analysis shown is from at least three biological replicates for each sample run in triplicate on each qPCR plate; error bars correspond to the standard deviation of the biological replicates. $P$-values were calculated, by $t$-test, from the biological replicates. Specific primers used are listed in the Supplemental Material.

\section{RNA-seq}

Ten micrograms of total RNA was depleted of ribosomal RNA using the Invitrogen Ribominus kit. The resulting RNA fraction was subjected to first-strand cDNA synthesis using random primers in the presence of actinomycin D. Samples were cleaned up by applying reaction mix to mini G50 columns. The eluted sample was then subjected to second-strand synthesis with DNA polymerase I, DNA ligase, and dUNTPs in the presence of RNase H. This ensures that the cDNA strand complementary to the mRNA has dNTPs and that the other strand is specifically labeled with dUNTPs. The cDNA was purified by QIA-quick-QG columns and then sonicated using a Bioruptor and fragment size assessed by mini-gel electrophoresis. The fragmented cDNA was subsequently end repaired, A-tailed, and then ligated to adapters. After Qiagen column purification, the samples were size-selected on a $2 \%$ high-resolution agarose gel. Fragments corresponding to $175-350$ bp were excised from the gel and collected by Qiagen column purification. The fragments were then treated with UDGase to remove the labeled strand, and then the mRNA complementary cDNA strand was amplified by PCR and subjected to sequencing analysis using the Illumina GAII. Reads were mapped by bowtie to hg18, keeping only uniquely mapping genes and discarding all but one of clonal reads. RPKM was calculated as the number of reads per kilo base of exon model per million reads mapped.

\section{Data access}

Sequencing data have been submitted to the NCBI Gene Expression Omnibus (GEO) (http://www.ncbi.nlm.nih.gov/geo/) under accession number GSE28115.

\section{Acknowledgments}

We thank D. Black for the SNRNP70 antibody and N. Tanese for the GST-CBX3 expression construct. A.S. is supported by the Ruth 
L. Kirschstein National Research Service Award no. T32 CA009523 from the National Institutes of Health/National Cancer Institute. We thank Zhen Ye, Samantha Kuan, and Lee Edsall for assistance in high-throughput sequencing. This work is partly supported by funding from LICR, NIH, and CIRM to B.R., and NIH (RO1CA117907), NSF (MCB 0842974), and HHMI to J.M.E.

\section{References}

Abe K, Naruse C, Kato T, Nishiuchi T, Saitou M, Asano M. 2011. Loss of heterochromatin protein $1 \gamma$ reduces the number of primordial germ cells via impaired cell-cycle progression in mice. Biol Reprod 85: 1013-1024.

Allemand E, Batsche E, Muchardt C. 2008. Splicing, transcription, and chromatin: A menage a trois. Curr Opin Genet Dev 18: 145-151.

Black JC, Allen A, Van Rechem C, Forbes E, Longworth M, Tschop K, Rinehart C, Quiton J, Walsh R, Smallwood A, et al. 2010. Conserved antagonism between JMJD2A/KDM4A and HP1 $\gamma$ during cell cycle progression. Mol Cell 40: 736-748.

Brown KE, Guest SS, Smale ST, Hahm K, Merkenschlager M, Fisher AG. 1997. Association of transcriptionally silent genes with Ikaros complexes at centromeric heterochromatin. Cell 91: 845-854.

Cryderman DE, Grade SK, Li Y, Fanti L, Pimpinelli S, Wallrath LL. 2005. Role of Drosophila HP1 in euchromatic gene expression. Dev Dyn 232: 767774.

de Wit E, Greil F, van Steensel B. 2005. Genome-wide HP1 binding in Drosophila: Developmental plasticity and genomic targeting signals. Genome Res 15: 1265-1273.

de Wit E, Greil F, van Steensel B. 2007. High-resolution mapping reveals links of HP1 with active and inactive chromatin components. PLoS Genet 3: e38. doi: 10.1371/journal.pgen.0030038.

Dillon N. 2004. Heterochromatin structure and function. Biol Cell 96: 631637.

Dinant C, Luijsterburg MS. 2009. The emerging role of HP1 in the DNA damage response. Mol Cell Biol 29: 6335-6340.

du Chene I, Basyuk E, Lin YL, Triboulet R, Knezevich A, Chable-Bessia C,

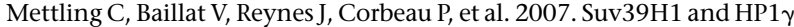
are responsible for chromatin-mediated HIV-1 transcriptional silencing and post-integration latency. EMBO J 26: 424-435.

Fanti L, Berloco M, Piacentini L, Pimpinelli S. 2003. Chromosomal distribution of heterochromatin protein 1 (HP1) in Drosophila: A cytological map of euchromatic HP1 binding sites. Genetica 117: 135147.

Feldman N, Gerson A, Fang J, Li E, Zhang Y, Shinkai Y, Cedar H, Bergman Y. 2006. G9a-mediated irreversible epigenetic inactivation of Oct-3/4 during early embryogenesis. Nat Cell Biol 8: 188-194.

Font-Burgada J, Rossell D, Auer H, Azorin F. 2008. Drosophila HP1c isoform interacts with the zinc-finger proteins WOC and Relative-of-WOC to regulate gene expression. Genes Dev 22: 3007-3023.

Greil F, van der Kraan I, Delrow J, Smothers JF, de Wit E, Bussemaker HJ, van Driel R, Henikoff S, van Steensel B. 2003. Distinct HP1 and Su(var)3-9 complexes bind to sets of developmentally coexpressed genes depending on chromosomal location. Genes Dev 17: 2825-2838.

Hawkins RD, Hon GC, Lee LK, Ngo Q, Lister R, Pelizzola M, Edsall LE, Kuan S, Luu Y, Klugman S, et al. 2010. Distinct epigenomic landscapes of pluripotent and lineage-committed human cells. Cell Stem Cell 6: 479-491.

Hediger F, Gasser SM. 2006. Heterochromatin protein 1: Don't judge the book by its cover! Curr Opin Genet Dev 16: 143-150.

Hiragami K, Festenstein R. 2005. Heterochromatin protein 1: A pervasive controlling influence. Cell Mol Life Sci 62: 2711-2726.

Huisinga KL, Brower-Toland B, Elgin SC. 2006. The contradictory definitions of heterochromatin: Transcription and silencing. Chromosoma 115: 110-122.

Hwang KK, Worman HJ. 2002. Gene regulation by human orthologs of Drosophila heterochromatin protein 1. Biochem Biophys Res Commun 293: $1217-1222$

Johnson DS, Mortazavi A, Myers RM, Wold B. 2007. Genome-wide mapping of in vivo protein-DNA interactions. Science 316: 1497-1502.

Kim TH, Barrera LO, Qu C, Van Calcar S, Trinklein ND, Cooper SJ, Luna RM, Glass CK, Rosenfeld MG, Myers RM, et al. 2005a. Direct isolation and identification of promoters in the human genome. Genome Res 15: 830 839.

Kim TH, Barrera LO, Zheng M, Qu C, Singer MA, Richmond TA, Wu Y, Green RD, Ren B. 2005b. A high-resolution map of active promoters in the human genome. Nature 436: 876-880.

Kwon SH, Workman JL. 2008. The heterochromatin protein 1 (HP1) family: Put away a bias toward HP1. Mol Cells 26: 217-227.

Kwon SH, Florens L, Swanson SK, Washburn MP, Abmayr SM, Workman JL. 2010. Heterochromatin protein 1 (HP1) connects the FACT histone chaperone complex to the phosphorylated CTD of RNA polymerase II. Genes Dev 24: 2133-2145.

Lenasi T, Barboric M. 2010. P-TEFb stimulates transcription elongation and pre-mRNA splicing through multilateral mechanisms. RNA Biol 7: 145150 .

Li Z, Van Calcar S, Qu C, Cavenee WK, Zhang MQ, Ren B. 2003. A global transcriptional regulatory role for c-Myc in Burkitt's lymphoma cells. Proc Natl Acad Sci 100: 8164-8169.

Licatalosi DD, Darnell RB. 2010. RNA processing and its regulation: Global insights into biological networks. Nat Rev Genet 11: 75-87.

Liu B, Tahk S, Yee KM, Fan G, Shuai K. 2010. The ligase PIAS1 restricts natural regulatory T cell differentiation by epigenetic repression. Science 330: 521-525.

Lomberk G, Wallrath L, Urrutia R. 2006. The heterochromatin protein 1 family. Genome Biol 7: 228. doi: 10.1186/gb-2006-7-7-228.

Maison C, Almouzni G. 2004. HP1 and the dynamics of heterochromatin maintenance. Nat Rev Mol Cell Biol 5: 296-304.

Mateescu B, Bourachot B, Rachez C, Ogryzko V, Muchardt C. 2008. Regulation of an inducible promoter by an HP1 $1 \beta-H P 1 \gamma$ switch. EMBO Rep 9: 267-272.

Moore MJ, Proudfoot NJ. 2009. Pre-mRNA processing reaches back to transcription and ahead to translation. Cell 136: 688-700.

Motamedi MR, Hong EJ, Li X, Gerber S, Denison C, Gygi S, Moazed D. 2008. HP1 proteins form distinct complexes and mediate heterochromatic gene silencing by nonoverlapping mechanisms. Mol Cell 32: 778-790.

Nielsen SJ, Schneider R, Bauer UM, Bannister AJ, Morrison A, O'Carroll D, Firestein R, Cleary M, Jenuwein T, Herrera RE, et al. 2001. Rb targets histone H3 methylation and HP1 to promoters. Nature 412: 561-565.

Ogawa H, Ishiguro K, Gaubatz S, Livingston DM, Nakatani Y. 2002. A complex with chromatin modifiers that occupies E2F- and Mycresponsive genes in G0 cells. Science 296: 1132-1136.

Perales R, Bentley D. 2009. "Cotranscriptionality": The transcription elongation complex as a nexus for nuclear transactions. Mol Cell 36: 178-191.

Piacentini L, Fanti L, Berloco M, Perrini B, Pimpinelli S. 2003. Heterochromatin protein 1 (HP1) is associated with induced gene expression in Drosophila euchromatin. J Cell Biol 161: 707-714

Piacentini L, Fanti L, Negri R, Del Vescovo V, Fatica A, Altieri F, Pimpinelli S. 2009. Heterochromatin protein 1 (HP1a) positively regulates euchromatic gene expression through RNA transcript association and interaction with hnRNPs in Drosophila. PLoS Genet 5: e1000670. doi: 10.1371/journal.pgen.1000670.

Ryan RF, Schultz DC, Ayyanathan K, Singh PB, Friedman JR, Fredericks WJ, Rauscher FJ III. 1999. KAP-1 corepressor protein interacts and colocalizes with heterochromatic and euchromatic HP1 proteins: A potential role for Krüppel-associated box-zinc finger proteins in heterochromatin-mediated gene silencing. Mol Cell Biol 19: 43664378.

Saint-Andre V, Batsche E, Rachez C, Muchardt C. 2011. Histone H3 lysine 9 trimethylation and HP1 $\gamma$ favor inclusion of alternative exons. Nat Struct Mol Biol 18: 337-344.

Schultz DC, Ayyanathan K, Negorev D, Maul GG, Rauscher FJ III. 2002. SETDB1: A novel KAP-1-associated histone H3, lysine 9-specific methyltransferase that contributes to HP1-mediated silencing of euchromatic genes by KRAB zinc-finger proteins. Genes Dev 16: 919932.

Shepard PJ, Hertel KJ. 2009. The SR protein family. Genome Biol 10: 242. doi: 10.1186/gb-2009-10-10-242.

Sims RJ III, Trojer P, Li G, Reinberg D. 2006. Methods to identify and functionally analyze factors that specifically recognize histone lysine methylation. Methods 40: 331-338.

Singh PB, Georgatos SD. 2002. HP1: Facts, open questions, and speculation. J Struct Biol 140: 10-16.

Smallwood A, Esteve PO, Pradhan S, Carey M. 2007. Functional cooperation between HP1 and DNMT1 mediates gene silencing. Genes Dev 21: 1169_ 1178.

Smallwood A, Black JC, Tanese N, Pradhan S, Carey M. 2008. HP1-mediated silencing targets Pol II coactivator complexes. Nat Struct Mol Biol 15: 318-320.

Song JS, Johnson WE, Zhu X, Zhang X, Li W, Manrai AK, Liu JS, Chen R, Liu XS. 2007. Model-based analysis of two-color arrays (MA2C). Genome Biol 8: R178. doi: 10.1186/gb-2007-8-8-r178.

Takanashi M, Oikawa K, Fujita K, Kudo M, Kinoshita M, Kuroda M. 2009. Heterochromatin protein $1 \gamma$ epigenetically regulates cell differentiation and exhibits potential as a therapeutic target for various types of cancers. Am J Pathol 174: 309-316.

Tilgner H, Guigo R. 2010. From chromatin to splicing: RNA-processing as a total artwork. Epigenetics 5: 3. 
Vakoc CR, Mandat SA, Olenchock BA, Blobel GA. 2005. Histone H3 lysine 9 methylation and HP1 $\gamma$ are associated with transcription elongation through mammalian chromatin. Mol Cell 19: 381-391.

Vassallo MF, Tanese N. 2002. Isoform-specific interaction of HP1 with human TAFII130. Proc Natl Acad Sci 99: 5919-5924.

Vicent GP, Ballare C, Nacht AS, Clausell J, Subtil-Rodriguez A, Quiles I, Jordan A, Beato M. 2006. Induction of progesterone target genes requires activation of Erk and Msk kinases and phosphorylation of histone H3. Mol Cell 24: 367-381.

Vogel MJ, Guelen L, de Wit E, Peric-Hupkes D, Loden M, Talhout W, Feenstra M, Abbas B, Classen AK, van Steensel B. 2006. Human heterochromatin proteins form large domains containing KRAB-ZNF genes. Genome Res 16: $1493-1504$.

Wysocka J, Swigut T, Milne TA, Dou Y, Zhang X, Burlingame AL, Roeder RG, Brivanlou AH, Allis CD. 2005. WDR5 associates with histone H3 methylated at $\mathrm{K} 4$ and is essential for $\mathrm{H} 3 \mathrm{~K} 4$ methylation and vertebrate development. Cell 121: 859-872.

Yahi H, Fritsch L, Philipot O, Guasconi V, Souidi M, Robin P, Polesskaya A Losson R, Harel-Bellan A, Ait-Si-Ali S. 2008. Differential cooperation between heterochromatin protein HP1 isoforms and MyoD in myoblasts. J Biol Chem 283: 23692-23700.

Yin H, Sweeney S, Raha D, Snyder M, Lin H. 2011. A high-resolution wholegenome map of key chromatin modifications in the adult Drosophila melanogaster. PLoS Genet 7: e1002380. doi: 10.1371/journal.pgen. 1002380.

Zeng W, Ball AR Jr, Yokomori K. 2010. HP1: Heterochromatin binding proteins working the genome. Epigenetics 5: 287-292.

Received April 14, 2011; accepted in revised form May 30, 2012. 


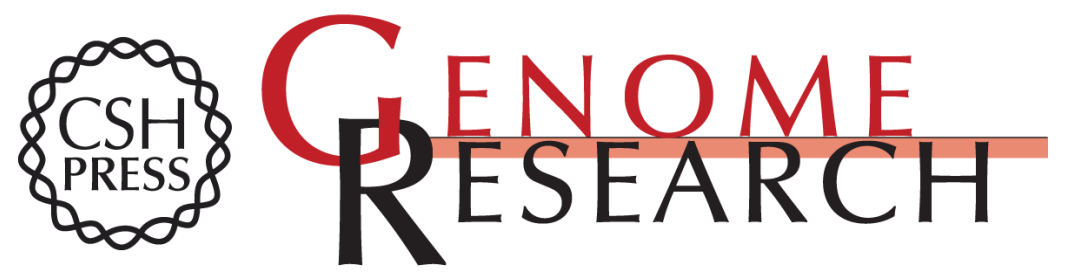

\section{CBX3 regulates efficient RNA processing genome-wide}

Andrea Smallwood, Gary C. Hon, Fulai Jin, et al.

Genome Res. 2012 22: 1426-1436 originally published online June 8, 2012

Access the most recent version at doi:10.1101/gr.124818.111

Supplemental http://genome.cshlp.org/content/suppl/2012/06/06/gr.124818.111.DC1
Material

References This article cites 57 articles, 17 of which can be accessed free at: http://genome.cshlp.org/content/22/8/1426.full.html\#ref-list-1

Creative This article is distributed exclusively by Cold Spring Harbor Laboratory Press for the Commons first six months after the full-issue publication date (see

License http://genome.cshlp.org/site/misc/terms.xhtml). After six months, it is available under a Creative Commons License (Attribution-NonCommercial 3.0 Unported License), as described at http://creativecommons.org/licenses/by-nc/3.0/.

Email Alerting Receive free email alerts when new articles cite this article - sign up in the box at the Service top right corner of the article or click here.

\section{Affordable, Accurate Sequencing.}

To subscribe to Genome Research go to:

https://genome.cshlp.org/subscriptions 